\title{
The Impact of Neighbourhood Churches on House Prices
}

\author{
Gabriel Kayode Babawale, PhD. \\ Department of Estate Management, University of Lagos, Nigeria \\ Tel: 234-80-2316-6473Ｅ-mail: gkbabs@yahoo.co.uk \\ Yewande Adewunmi, M.Sc. \\ Department of Estate Management, University of Lagos, Nigeria \\ E-mail: yewande_adewunmi@yahoo.com
}

\begin{abstract}
This study extends literature that empirically investigates the impact of neighborhood churches on residential property values with particular reference to selected areas in Lagos metropolis. The hypothesis that proximity to a church has no effect (positive or negative) on house prices is tested with a standard hedonic pricing model using a sample of 450 rented apartments (flats) across the study areas. The results followed the more common belief that neighborhood churches, particularly the large ones, impact negatively on the values of nearby residential properties. It further revealed that where more powerful positive externalities exist in close proximity, the negative effects of churches, even the large ones, on residential property values can be neutralized or even overshadowed. Among others, the results of the study is expected to bring to light the social and economic implications of churches located within residential neighborhoods in the study area and thereby assist urban planners, the courts and real estate valuers in resolving the debate on the nuisance versus amenity effects of neighborhood churches.
\end{abstract}

Keywords: Neighbourhood churches, Externalities, House prices, Hedonic model, Nigeria

\section{Background to the Study}

There is a growing recognition that property development, use and management should be evaluated against criteria that embody sustainability measures. That is, genuine sustainability evaluations should balance social, cultural and economic performance measures with environmental protection (Body, 2005). In this regard, location of churches within residential neighborhoods has been an issue of concern and controversy in several societies. The question remains whether the externalities exhibited by churches are positive (amenities) or negative (nuisance or disamenities). Existing empirical studies are inconclusive and anecdotal evidences are mixed.

The notion of "externalities" is a useful concept developed in welfare economics. In real estate parlance, the notion of externalities states that external factors to a property can have either positive or negative effects on its value (Appraisal Institute, 2008; Do et al., 1994). Because of its physical immobility, real estate tends to be affected by externalities more strongly than most other economic goods, services, or commodities. Ascertaining the effects of externalities on property values provide a very strong test of the nuisance versus amenities effects. If an externality is truly a nuisance, then values of properties within close range will be adversely affected in proportion to the distance from it. If on the other hand an externality is an amenity, then property value will increase the closer a property is located to it.

Example of externalities that are associated with negative effects on values of residential properties in close proximity are landfill (Arimah \& Adinnu, 1995); brownfield (Kaufman \& Cloutier, 2006) contaminated properties (Kohlashe, 1991; Kinnard \& Geckler, 1991); air pollution (Hamilton \& Biggs, 1993; Komarova, 2009); industrial sites (Vor \& Groot, 2009); oil and natural gas facilities (Chan \& McMillian, 2004); and nuclear plant and iron and steel plant (Bilbao-Terol, 2009). On the other hand, land uses that constitute positive externalities include water view (Seiler et al., 2001; Paterson \& Boyle, 2002; Bourassa et al., 2004); open spaces, parks and greenbelt (Bolitzer \& Netusil, 2000; Asabere \& Huffman, 2007); golf course (Nichollis \& Crompton, 2007); and neighbourhood schools (Ketkar, 1992; Zahirovic-Herbert, 2007).

At present, there is paucity of studies on the effect of neighborhood churches on the values of nearby residential properties. The few existing studies revealed varied magnitude and direction of impact: ranging from negative, to insignificant, and to positive impact (Do et al., 1994; Thomas et al., 1996). In the developed nations, the paucity of studies could be attributed to effective planning (zoning regulation) that has curtailed indiscriminate location of religious premises. For example, the US has the Religious Land Use and Institutionalized Persons Act (RLUIPA), a federal law that profoundly makes churches to adhere to zoning regulations. Thus, Clowney (2007) observed that the Zoning Boards have so far successfully pressured religious institutions to limit their physical presence in 
American cities and towns thereby making residential neighborhoods very reserved areas. Only few studies have therefore been carried out in the US on the subject including Do et al., (1994); Carroll et al., (1996); Ottensmann (2000); and that of the Centre for Urban Policy and the Environment (2006). In Nigeria where there are larger number of churches which are often indiscriminately located within residential neighborhood, effect of neighborhood churches on residential property values has not been seriously investigated.

Noise from church bells, loud speakers and musical instruments, people arriving and departing the premises, traffic and parking problems, pollution from automobiles, operating hours extending from morning till evening, and people of different shades and characters trooping into the neighborhood are parts of the negative externalities generated by neighborhood churches (Do et al., 1994). Brogan (1991) also identified architectural incompatibility of church buildings with residential structures and the loss of view amenities, as some other negative effects of churches on residential property prices. In Nigeria, Pentecostal churches are particularly noted for unmatched zeal; exuberance; loud singing, clapping, bell ringing and drumming; and in some cases with loud speakers mounted on roof tops or the facial boards. Weekly meetings for Pentecostal churches are numerous, besides the monthly or weekly vigils and conventions that draw adherences from across the country and beyond. Other negative effects include the apparent traffic congestion on service days and other special events with the attendant parking problems and pollution from automobile exhaust, and in isolated cases, robbery attack within the vicinity. Nelson (2008) argued that environmental noises that exceed ambient levels can disturb valuable activities such as conversation, TV viewing, leisure, work or sleep and that in several cases can have adverse effects on long-term health and thereby reduce productivity and quality of life. Irritating noise level in the neighborhood also contributes to more violent and aggressive behavior.

Churches on the other hand do exhibit certain potentially positive externalities. Thomas et al., (1996) concluded that neighborhood churches are amenities that enhance residential property values because they create positive externalities such as a symbol of morality and serving as a hub of commercial activities that draws people together for worship and socials; providing peace in the form of a respite from commercial and family concerns; operating schools ranging from day-care for children and aged, secondary and vocational, and in some cases, a university.

A study on externalities by Do et al., (1994) used information on 469 single-family residential dwellings sold in metropolitan Chula, Vista, California gathered between January 1991 and September 1992, to test the null hypothesis that proximity to a church building has no effects on residential property values. Using a standard hedonic pricing model, the study produced a regression equation for the natural logarithm of selling price in terms of externalities variables of distance and distance squared as follows:

$\operatorname{Ln}\left(\mathrm{PS}_{\mathrm{i}}\right)=\ldots .+0.6008 * \operatorname{DIST}_{\mathrm{i}}\left(10^{-4}\right)-3.5346 * \operatorname{DIST}_{\mathrm{i}}^{2}\left(10^{-8}\right)$

A significant positive value of the coefficient of DIST $_{i}$ in the resultant model (significant at the $5 \%$ level), and negative coefficient of DIST $_{i}^{2}$ (also significant at the 1\% level) suggests that neighborhood churches exhibit negative externalities on single-family house price with selling price of a home increasing with increased distance from a church building. Results indicate the effect of churches on sales price is negative up to approximately 850 feet.

Carroll et al., (1996) were inspired by the results of Do et al., (1984) to investigate the impact of neighborhood churches on residential property values using a sample of nearly 5,000 residential property transactions in Henderson, Nevada, between January 1986 and December 1990. In contrast to the findings of Do et al., (1994), the later study found that neighborhood churches are amenities that enhance property values because they create positive externalities. They found out that people prefer to stay close to religious places of worship so as to reduce costs of commuting. Carroll et al., (1996) bolstered their findings by showing that distance from the site of a future church has little or no impact on residential property values, whereas distance from an existing church is associated with lower property values.

The only known study in Nigeria was conducted by Iroham and Oloyede (2010). The authors used the Living Faith Church, Ota, Ogun State, Nigeria to investigate the impact of religious property on nearby residential property values. The mean of residential property values before and after the siting of the church were compared, and suggested that the church had tremendous impact on the values of surrounding residential properties. This study exhibited apparent methodology limitations. Given that the factors affecting property values are many and diverse; the mean difference would not have captured the relative impact of the religious property on residential property values convincingly. Studies on the impact of externalities are traditionally investigated using the hedonic price model (Rosen, 1974; Kohlashe, 1991; Arimah \& Adinnu, 1995). The study is therefore neither persuasive nor conclusive. It is therefore still uncertain whether the externalities generated by neighborhood churches are viewed by the market as positive or negative in Nigeria. Hence, the need for further studies on the subject. This study 
therefore focuses on evaluating the impact of selected churches in Lagos metropolis on prices of nearby residential properties. The paper is arranged in sections and the introductory section is followed by a description of the study area. The methodology employed in the study and nature of the variables followed respectively. Finally is a discussion on the empirical results and the conclusions.

\section{The Study Area}

The study area is Lagos metropolis. This study is particularly relevant and crucial to a nation like Nigeria, and especially metropolitan Lagos - the hub of Nigeria's commercial and industrial activities. First, in Nigeria, churches are built with less emphasis on zoning regulations such that religious premises are dotted indiscriminately in virtually all residential neighborhoods. Secondly, Nigeria is reputed as one the most religious nations in the world. Her Christian population is estimated at over 50 million (43\% of her 120 million total population), a large percentage of which are Pentecostals. Living Faith, one of the numerous Pentecostal denominations, is reported to have the largest church auditorium in the world (Guinness Book of Records, 2008); has over 1000 satellite fellowship centres dotted over Lagos and environs. An average of over 25000 vehicles (private and public) is said to enter the main church premises every Sunday for the three Sunday services in the 50 000 capacity auditorium. The Redeemed Church of God, another notable Pentecostal denomination, undoubtedly the fastest growing church denomination in the world, has over 2,500 church networks within Lagos metropolis alone, with congregation numbering between less than 30 to over 3,500. These are just two out of hundreds of Pentecostal denominations fully represented within the metropolis. The impact of the externalities generated by these numerous centers of worship on the values of nearby residential buildings as well as their implications on urban zoning policies and pricing of residential properties in the study area cannot be over emphasized making it worthy of empirical investigation.

\section{Methodology}

Three churches were selected for the empirical investigation/analysis. They are, Mountain of Fire and Miracle Ministries, Onike; Deeper Life Bible Church, Gbagada; and Christian Pentecostal Mission, at Ajao Estate. Ajao Estate is predominantly a medium density residential neighborhood with owner-occupied detached houses and rented apartment (flats) constituting the bulk of the property stock. It is the immediate residential neighborhood to the Murtala Mohammed International Airport (Nigeria's chief airport) along the principal access route to the airport. Majority of residents are within the middle income and the lower-upper income brackets. Gbagada, where the Deeper Life Bible Church locates, is an extensive and predominantly residential neighborhood intermingled with low and medium density residences. The immediate surrounding of the church under reference is medium density with rented apartment being the predominant development. Mountain of Fire and Miracle Church's immediate neighborhood is medium density with development comprising mainly of block of flats intermingled with detached houses and bungalows. The church shares boundary with the University of Lagos, by the University's second gate.

In each of the study area, distance from church premises is divided into three zones A, B, C with a distance of 50 metres, 100 metres, and 150 metres respectively. In each of the zones of each study area, 50 heads of households were served with questionnaires to fill using the purposive sampling method since only occupiers of apartment (flats), with house rent contracted within the last 2 years prior to the time of the survey were the targeted respondents. A total of 450 questionnaires were therefore administered in all the 9 zones. This sample size is considered reasonable given the homogeneous characteristics of the study areas. The sample objects, rooming apartments (flats), are also largely homogenous. The questionnaire survey sought information on rental values and residential property attributes and was conducted over two (2) months (between June and July, 2010).

Each of the three churches has a large congregation going by the size of the congregation, the volume of vehicular and human traffic generated at every meetings and special events (frequency of meeting times vary but takes place, in some churches, virtually every day of the week). In Nigeria, and especially in Lagos metropolis, the effects of small churches on neighboring residential properties may be rather difficult to gauge due to their large number, and their close juxtaposition all over the metropolis. It is also conceivable that small churches are less intimidating to neighborhood residents than large churches are. Carroll et al., (1996) is of the opinion that if noise and traffic is the major disruptions caused by churches, then we should expect that bigger churches would create correspondingly greater externalities. If larger churches are greater nuisance than smaller churches, as reported by Do et al., (1994), then larger churches should have greater effects (adverse) on the prices of neighboring residential properties. If on the other hand, churches are amenities as Carroll et al., (1996) posited, then larger churches should enhance values of nearby properties more than smaller churches. 
The study employs the standard hedonic pricing model to test the null hypothesis that the presence of neighborhood churches has no significant impact on the values of nearby residential properties. The hedonic approach remains the most adequate and well-accepted tool for untangling the cross-influences between the numerous dimensions affecting property values and for establishing the implicit price of individual residential attributes (Des Rosiers et al., 2001). At its simplest, a hedonic equation is a regression of expenditure (rental or capital values) on characteristics that determine house rent or capital value. The model assumes that value of houses can be decomposed into the value of its constituent characteristics (e.g. bedrooms, bathrooms, distance from amenities, age etc.) and the model provides estimates of the marginal contribution of each property attribute to the total price (Rosen, 1974).

The empirical specification of the hedonic price model is therefore of the form:

$$
\mathrm{P}=\beta_{0}+\beta_{\mathrm{j}} \mathrm{X}_{\mathrm{j}}+\beta_{\mathrm{d}} \mathrm{X}_{\mathrm{d}}+\mathrm{u}
$$

Where,

$$
\begin{aligned}
& \mathrm{P}=\text { property value ( the dependent variable). } \\
& \beta_{0}=\text { a constant term } \\
& \beta_{\mathrm{j}}=\text { estimated coefficients for continuous variables. } \\
& \beta_{\mathrm{d}}=\text { estimated coefficients for distance variable. } \\
& \mathrm{X}_{\mathrm{j}}=\text { jth property characteristic. } \\
& X_{\mathrm{d}}=\text { distance to church. } \\
& \mathrm{u}=\text { the error term. }
\end{aligned}
$$

Previous research has identified a number of housing characteristics or attributes that impact on their prices. Kauko (2003) listed accessibility factors, neighborhood quality factors, specific negative externalities, public service, taxes, and identity factors. McCluskey et al., (2000) in their study of Hong Kong housing market emphasized the date of sale, age of property, size, number of bedroom and bathrooms, number of garages, type of central heating, condition, neighborhood and group cluster. Love (2000) in a similar Hong Kong study, classified the attributes into four categories namely: structural, physical, neighborhood and environmental. Bello (2008), a Nigerian study, grouped the attributes into those that are internal and those that are external to the property. Internal attributes essentially comprise the intrinsic characteristics of the property such as size, number of accommodation, condition, aesthetics, layout, age, and plot size, while external attributes include the general state of the economy, population, employment, immigration, finance, location, infrastructure, transportation and neighborhood attributes.

Megbolugbe (1988) in his study of housing market in Jos, Nigeria, classified the traits into three categories: structural traits (square meters, building age, roof cover, and plumbing fixtures); neighborhood traits (school quality, road quality, and availability of electricity, water and other vital public services); and locational traits (access to economic, social , and political activities such as distance to CBD, shopping centers, parks, and other recreational facilities). These studies suggest that attributes employed in a particular study must be related and relevant to the specific market under consideration; reflecting the primary factors which influence the expectations and perceptions of participants in that particular market - the way they make up their mind on price.

Since the externality effects of church proximity on rental value of apartment buildings is our main focus in this study, the hedonic equation for this study would be of the form:

$$
R V_{i}=f\left(X_{i j}, D_{I S T}\right)
$$

Where,

- $\quad \mathrm{RV}_{\mathrm{i}}$ is the rental value of apartments (flats);

- $\quad \mathrm{X}_{\mathrm{ij}}$ is a set of explanatory housing-rent variables (housing/neighborhood attributes) for a given property $\mathrm{i}$;

- $\quad$ DIST $_{\mathrm{i}}$ is the distance of property i from the nearest neighborhood church property measured in meters (approximately).

The set of $\mathrm{j}^{\text {th }}$ housing-rent variables considered relevant to the study area that were used in this study are:

D_REG $=$ distance to religious property, in meters (approximately).

PARKING = number of availabile parking lots.

ROOM $=$ number of bedrooms

BATH $=$ number of bath/toilets 


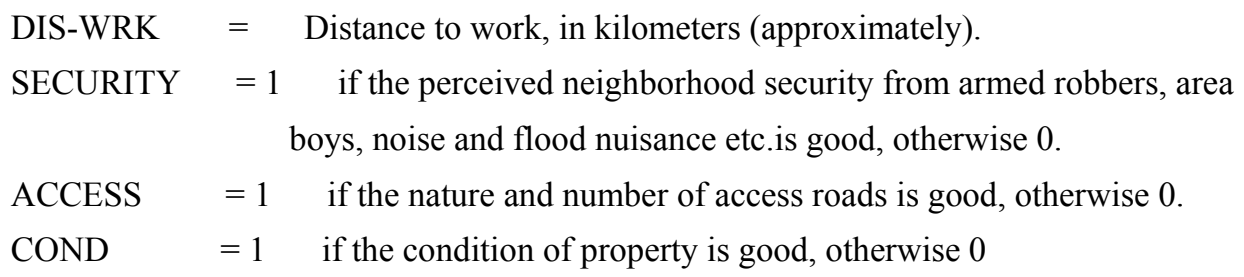

Distance from church variable, D_REG, captures the effect of proximity to a religious property on rental values of nearby residential properties. The other variables, except age and distance to work, are expected to have a positive influence on rental values. Age of property is however excluded from the variables because rental values (unlike capital values) does not respond so much to the age of properties but rather to the present condition of the property. Thus, in the model the condition of the property ('housing condition') is used.

A significant positive coefficient value for D_REG in the estimated model is evidenced by negative externalities associated with religious properties since such a positive coefficient value indicates that the rental value of a residential property increases as distance from a religious property increases. On the other hand, a significant negative coefficient value provides evidence of positive externalities associated with religious properties indicating that the rental values of a residential property decreases as distance from a religious property increases.

\section{Empirical Results}

The summary statistics of the analyzed variables are presented in Tables 1-3. F- statistics for the three models are highly significant at the $1 \%$ level, and $\mathrm{R}^{2}$ values are high and similar across the models. These suggest that a very high significance could be placed on the results and that the eight housing attributes sufficiently account for variation in house prices in the study area. A number of the variables exhibited unexpected signs in their correlations with housing price. Oxford (1999) suggests that spatial effects. The t-value column provides the individual significance of each independent variable in the regression equation and tells whether the variable is making statistically significant contribution. A variable must have a significant value of less than 0.05 to make significant unique contribution. The Durbin-Watson value for each of the three models indicates that there are no autocorrelation among the independent variables.

\section{Insert Table 1 Here}

Table 1 presents the summary of the results of the regression analysis for the Mountain of Fire and Miracle Ministries. Only three of the attributes make statistically unique contribution to house prices at $99 \%$ confidence level namely:

- number of bedrooms,

- number of toilet/bath

- distance from church.

The standardized beta coefficients which provide the order of importance or relative contribution of the housing attributes show that number bedrooms make the largest contribution, followed by number of bath/toilet, and then distance from church. The multiple regressions equation that relates house prices (Hp) to the housing attributes is given by the constant and the coefficient of the unstandardized beta as:

$\mathrm{Hp}=-374791.42+20400.28 \mathrm{~N}_{\mathrm{r}}+168560.69 \mathrm{~N}_{\mathrm{bt}}-393.02 \mathrm{D}_{\mathrm{ch}}-24042.385 \mathrm{H}_{\mathrm{cd}}+7922.87 \mathrm{P}_{\mathrm{lt}}-16024.33 \mathrm{~N}_{\mathrm{st}}+3$ $452.60 \mathrm{R}_{\mathrm{cd}}+18563.16 \mathrm{D}_{\mathrm{w}}$

The equation shows that it is only number of rooms, number of toilet/bath, availability of parking lot, condition of access road, and distance from work are positively correlated to house price. One unit increase in the number of bedroom and bath/toilets results in N20,400.28 and N16,560.69 ( $\mathrm{N}=$ Nigeria Naira) increase in house rent, respectively. The expected negative sign is found between house price and house condition but is not significant at the 0.1 level. The negative correlation of housing price with perceived level of security in the neighborhood though not statistically significant at the $1 \%$ level is spurious. A combination of poor yields on investment properties (average 51/2 \% per annum), high costs of maintenance, and tenants' poor capability to effect repairs even when it is their covenant responsibility, may be responsible for little regard to the state of buildings as high level of disrepair is today a commonplace. The apparent indifference to perceived level of security might be due to the general feeling of insecurity that envelops the whole nation, particularly, the urban centers.

More significantly, distance to church, our principal concern in this study, is negatively correlated contrary to more popular belief. The negative coefficient (significant at $99 \%$ confidence level) indicates that apartment renters pay more for houses in close proximity to the church than those farther away. The 'unexpected' negative correlation 
can be attributed, in part, to the proximity of the church under consideration to the University of Lagos main campus, with its very strong positive externalities effects on house (particularly flats) prices. Shortage of campus accommodation for the ever growing number of both staff and students has continued to put pressure on available stock of residential accommodation within its vicinity which seemed to be potent enough to counter the negative externalities associated with the church. With supply outstripping demand, renters may have been forced to play down on negative externalities of church. That may also inform the reason why distance from work is positively correlated, though statistically insignificant.

It may be concluded therefore that where negative and positive externalities locate in close juxtaposition, the ultimate effects on residential property values will depend on the relative strength of the two.

\section{Insert Table 2 Here}

Table 2 summarizes the results of the regression analysis for the Deeper Life Bible Church, Gbagada. Curiously, only three of the eight explanatory variables are positively correlated viz:

- number of bedrooms

- number of bath/toilets

- distance from church.

The number of bedrooms again is the dominant factor followed by the number of toilet/baths. All other factors are negatively correlated including surprisingly, perceived neighborhood security level, availability of parking facilities, road condition and distance to work.

Though not statistically significant at the required level of confidence, the positive sign of the coefficient for distance from church suggests that neighborhood churches impact negatively on values of nearby residential properties such that house prices increase by approximately $\mathrm{N} 310$ for every additional one metre distance away from a church premises and vice-versa. The resultant regression equation is given by:

$\mathrm{Hp}=-226949.00+269152.49 \mathrm{~N}_{\mathrm{r}}+134979.24 \mathrm{~N}_{\mathrm{bt}}+309.80 \mathrm{D}_{\mathrm{ch}}-20871.87 \mathrm{H}_{\mathrm{cd}}-70859.31 \mathrm{P}_{\mathrm{lt}}-5060.78 \mathrm{~N}_{\mathrm{st}}-54$ $838.14 \mathrm{R}_{\mathrm{cd}}-17184.48 \mathrm{D}_{\mathrm{v}}$

\section{"Insert Table 3 Here"'}

Table 3 presents the summary of the results of the regression analysis for Christian Pentecostal Mission in Ajao Estate. The D_REG coefficient is positive and statistically significant at $99 \%$ confidence level throughout the entire study area suggesting that the church is viewed in the neighborhood as a disamenity that impact negatively on the prices of residential properties. Hence, rental value of a home increases as distance from church increases and vice-versa.

$\mathrm{Hp}=-524066.53+308790655 \mathrm{~N}_{\mathrm{r}}+97071.68 \mathrm{~N}_{\mathrm{bt}}+867.91 \mathrm{D}_{\mathrm{ch}}-44006.44 \mathrm{H}_{\mathrm{cd}}+25294.92 \mathrm{P}_{\mathrm{lt}}+1099.48 \mathrm{~N}_{\mathrm{st}}-17$ $409.12 \mathrm{R}_{\mathrm{cd}}-19538.96 \mathrm{D}_{\mathrm{wk}}$

\section{Conclusions}

This study empirically examines the effects of religious properties on rental values of nearby residential properties. Findings do not depart markedly from the findings of Do et al., (1994) that neighborhood churches generate more negative than positive externalities resulting in adverse effects on the prices of residential properties in close proximity. The exception to this rule, of course, is the overriding effects of more powerful positive externalities in close juxtaposition.

The conclusion therefore is that religious properties constitute negative externalities, however, the presence of a positive externality adjacent a negative externality could distort the result. This result is beneficial to both public and private parties involved in land use decisions, especially, zoning. It will also assist the judiciary in resolving litigation bordering on location of churches within residential neighborhood. Moreover, it is imperative that real estate valuers' appreciate the full implications of externalities as part of their considerations in valuation of residential properties. Valuers are therefore encouraged to review their valuation models to accommodate the different sustainability scenarios by varying the key inputs for differing environmental or social benchmark levels such as using weighted sustainability criteria in addition to the traditional valuation factors (Boyd, 2005).

In conclusion, further research needs to be carried out to establish this conclusion for the entire metropolitan Lagos. This study only examines the externality effects of religious properties on nearby residential properties (flats). It may be necessary to also investigate the effects of religious properties on other categories of residential properties, in other neighborhoods of different socio-economic characteristics and on non-residential properties in different locations within the metropolis. 


\section{References}

Boyd, T.P. (2005). Can we Assess the Worth of Environmental and Social Characteristics in Investment Property? A Paper Presented at $11^{\text {th }}$ Pacific Rim Real Estate Society Conference, 2005.

Bourassa S.C., Hoesli, M. \& Sun, J. (2004). What's in a View? Environmental and Planning A. 36(8): pp 1427-50.

Boxall, P. C., Chan, W. H., \& McMillan, 1. (2005). The Impact of Oil and Natural Gas Facilities on Rural Residential Property Values: A Spatial Hedonic Analysis. Resource and Energy Economic 27(4)248-269.

Carrol T.M.., Clauretie T.M., \& Jensen J. (1996). Living Next to Godliness: Residential Property Values and Churches. Journal of Real Estate Finance and Economics, 12: 319-330.

Dimke, M.S. (2008). Valuation of Tree Canopy on Property Values of Six Communities in Cincinnati, Ohio. Unpublished PhD. Dissertation, Ohio State University.

Do A. Q., Wilbur R.W., \& Short J. L. (1994). An empirical Examination of the Externalities of Neighbourhood Churches on Housing Values. Journal of Real Estate Finance and Economics, 9: 127-136.

Iroham, C.O. \& Oloyode, S. A. (2010). Location of Worship Centres and Its Effect on Residential Property Values (a case of Living Faith Church, Ota). A Paper Delivered at the First National Conference, Department of Urban and Regional Planning, University of Lagos. Emerging Global City: The African Challenge.

Ben C. A. \& Frank, I. A. (1995). Market Segmentation and the Impact of Landfills on Residential Property Valuers: Empirical Evidence from an African City. Journal of Housing and the Built Environment, 10(2), 157-171.

Friso De Vor \& Henri L. F. de Groot. (2009). Impact of Industrial Sites on Residential Property Value: A Hedonic Pricing Analysis for the Netherlands. A Tinbergen Institute Discussion Paper.

Kaufman D. A. \& Cloutier N. R. (2006). The Impact of Small Brownfields and Greenspaces on Residential Property Values. Journal of Real Estate and Economics, 33: 19-30.

Kohlhase, J. E. (1991). The Impact of Toxic Waste Sites on Housing Values. Journal of Urban Economics, 30 (1) p.1-26.

Komarova V. (2009). Valuing Environmental Impact of Air Pollution in Moscow with Hedonic Prices. World Academy of Science, Engineering and Technology 57.

Megbolugbe, I.F. (1989). A Hedonic Index Model: The Housing Market of Jos, Nigeria. Urban Studies Journal Limited,26;486.

Paterson R. W., \& Boyle, K. J. (2002). Out of Sight, Out of Mind? Using GIS to Incorporate Visibility in Hedonic Property Value Models. Land Economics, 78(3).

Richard C. R. (2005). Do Landfills Always Depress Nearby Property Values? Rural Development Paper (27).

Rosen S. (1974). Hedonic Prices and Implicit Markets: Product Differentiation in Pure Competition. Journal of Political Economics, 82:34-55.

Seiler, M. J., Bond, M. T., \& Seiter, V. L. (2001). The Impact of World Class Great Lakes Water Views on Residential Property Value. Appraisal Journal. 69 (3) 287-295. 
Table 1. Regression Results: Mountain of Fire and Miracle Ministries

\begin{tabular}{lcccc}
\hline Variable & beta weight & beta coefficient & t-value & Sig. \\
\hline Constant & -374791.417 & & -7.098 & .000 \\
No. of bedrooms & 204003.284 & 0.573 & 13.632 & .000 \\
No. of bath/toilets & 168560.692 & 0.432 & 9.956 & .000 \\
Distance to church & -393.018 & -.067 & -2.222 & .028 \\
House condition & -24042.375 & -.031 & -.996 & .321 \\
Parking space & 7922.871 & .016 & .524 & .601 \\
Neighborhood security & -16024.329 & -.025 & -.850 & .397 \\
Road condition & 3452.602 & .005 & -.177 & .859 \\
Distance to work & 18563.160 & .038 & 1.244 & .216 \\
& & & & \\
$\mathrm{R}^{2}=0.881$ (88.1\%); F-statistic $=130.519$ (p> .000); & Durbin Watson = $1.739 ;$ US\$=N150 & \\
\hline
\end{tabular}

Table 2. Regression Results: Deeper Life Bible Church, Gbagada

\begin{tabular}{|c|c|c|c|c|}
\hline Variable & beta weight & beta coefficient & t-value & Sig. \\
\hline Constant & -226948.999 & & -2.521 & .013 \\
\hline No. of bedrooms & 269152.485 & .611 & 10.327 & .000 \\
\hline No. of bath/toilets & 134979.236 & .303 & 5.052 & .000 \\
\hline Distance to church & 309.802 & 044 & 1.024 & .308 \\
\hline House condition & -20871.869 & -.032 & -.737 & .426 \\
\hline Parking space & -70859.309 & -1.115 & -2.636 & .009 \\
\hline Neighborhood security & -5060.783 & -.008 & -0.183 & .855 \\
\hline Road condition & -54838.142 & -.007 & -1.807 & .073 \\
\hline Distance to work & -17184.475 & -.030 & -0.0670 & .504 \\
\hline $\mathrm{R}^{2}=0.751(75.1 \%)$ & F-statistic $=53.184(\mathrm{p}>.000)$ & Durbin Watson & $=1.372$ & $\mathrm{~N}=150$ \\
\hline
\end{tabular}

Table 3. Regression Results: Christian Pentecostal Mission

\begin{tabular}{lcccc} 
Variable & beta weight & beta coefficient & t-value & Sig. \\
\hline Constant & -524066.528 & & -6.245 & .000 \\
No. of bedrooms & 308790.550 & .675 & 11.513 & .000 \\
No. of bath/toilets & 97071.684 & .224 & 3.843 & .000 \\
Distance to church & 867.912 & .129 & 2.898 & .004 \\
House condition & -44006.444 & -.079 & -1.781 & .077 \\
Parking space & 25294.920 & .046 & 1.018 & .310 \\
Neighborhood security & 1099.480 & .002 & .044 & .965 \\
Road condition & -17409.120 & -.028 & -.653 & .515 \\
Distance to work & -19538.958 & -.035 & -.807 & .421 \\
$\mathrm{R}^{2}=0.749(74.9 \%) ;$ & F-statistic $=52.538(\mathrm{p}>.000) ;$ & Durbin Watson $=1.185 ;$ & $\mathrm{N}=150$ \\
\end{tabular}

